\title{
Gerd Dietrich, Kulturgeschichte der DDR
}

\section{Elisa Goudin}

\section{OpenEdition \\ Journals}

Édition électronique

URL : http://journals.openedition.org/ifha/10128

DOI : 10.4000/ifha. 10128

ISSN : 2198-8943

Éditeur

IFRA - Institut franco-allemand (sciences historiques et sociales)

\section{Référence électronique}

Elisa Goudin, «Gerd Dietrich, Kulturgeschichte der DDR », Revue de l'IFHA [En ligne], Date de recension, mis en ligne le 13 juin 2019, consulté le 10 décembre 2020. URL : http://journals.openedition.org/ifha/ 10128 ; DOI : https://doi.org/10.4000/ifha.10128

Ce document a été généré automatiquement le 10 décembre 2020.

(CIFHA 


\title{
Gerd Dietrich, Kulturgeschichte der DDR
}

\author{
Elisa Goudin
}

\section{RÉFÉRENCE}

Gerd Dietrich, Kulturgeschichte der DDR. Band I: Kultur in der Übergangsgesellschaft 1945-1957; Band II: Kultur in der Bildungsgesellschaft 1957-1976; Band III: Kultur in der Konsumgesellschaft 1977-1990, Göttingen : Vandenhoeck\&Ruprecht, 2018, 2429 p., $99,99 €$ 
La publication de l'ouvrage de Gerd Dietrich sur la politique culturelle de la RDA a été un événement scientifique: 2429 pages très denses, en trois tomes. Il n'existait auparavant que très peu d'ouvrages de synthèse sur cette question, comme la Kulturgeschichte der DDR de Frank Hoffmann publiée en 2014 mais qui ne prenait pas suffisamment en compte la culture populaire. C'est aussi une réponse explicite de G. Dietrich à Axel Schildt et Detlef Siegfried, qui, dans leur Histoire culturelle allemande, Deutsche Kulturgeschichte parue en 2009, ne parlaient que très peu et totalement à la marge de la culture de RDA. D'une certaine façon, G. Dietrich a écrit l'œuvre qui lui manquait pendant toute sa carrière d'enseignant et de chercheur, ses travaux s'articulant presque tous autour de la vie

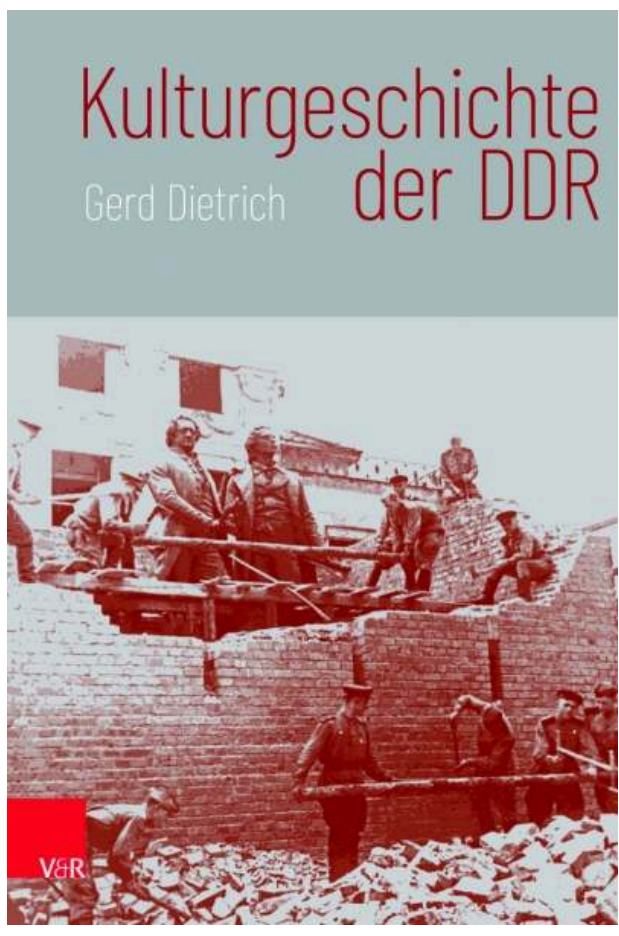
culturelle en RDA. On ne sera donc pas étonnés de voir la parution de cet ouvrage global, qui se présente comme une œuvre de référence et ressemble en ce sens, par son ampleur, à l'œuvre d'une vie pour un public très spécialisé. Une œuvre de maturité en quelque sorte. Il reste néanmoins très accessible, malgré, ou peut-être justement grâce aux très nombreux détails qui l'émaillent.

Si l'on devait résumer rapidement, il s'agit d'un ouvrage sur la complexité et les contradictions de la politique culturelle en RDA, qui met en évidence toutes les inflexions de cette politique au fil du temps : l'héritage de la culture classique allemande et de la culture bourgeoise du XIX ${ }^{\mathrm{e}}$ siècle, la révolution culturelle (Kulturrevolution) de Ulbricht et sa variante parfois nommée maoïste du Bitterfelder Weg, jusqu'à la notion de nation culturelle socialiste de RDA chère à Honecker (Sozialistische Kulturnation). Le réalisme socialiste comme méthode y est abordé. En ce sens, on peut parler d'un manuel de référence, un guide ou un catalogue, presque une notice d'explication de la politique culturelle de RDA. Il est très complet, même si l'auteur affirme dans le propos liminaire qu'il n'a pas d'ambition d'exhaustivité (p. XLI) et qu'il ne prétend à aucune vérité définitive (ce qui est toujours le cas des ouvrages scientifiques, réfutables par définition).

La notion de Kultur est comprise dans une acception très large, incluant la philatélie ou le sport par exemple. Cela ne surprend pas de la part d'un historien qui, né en 1945, a eu une carrière classique d'historien en RDA : après le bac, il passe deux années comme ouvrier à l'usine et entame ensuite des études supérieures d'histoire et de sport. Il travaille ensuite à l'Institut für Marxismus-Leninismus beim ZK der SED (IML) qui deviendra l'Akademie für Gesellschaftswissenschaften beim ZK der SED, institution phare pour l'étude des questions sociales et donc aussi historiques en RDA. Puis il est muté au Zentralinstitut für Geschichte der Akademie der Wissenschaften (AdW), moins contrôlé par le SED que l'IML. Comme beaucoup, il est critique, surtout pendant l'ère Gorbatchev. Sa première thèse sur la fondation du SED a été interdite en RDA car il n'avait « pas 
compris le lien entre démocratie et socialisme ", un reproche de révisionnisme, comme se souvient l'un de ses anciens thésards (voir Karsten Krampitz, "Vom Doktorvater ", Der Freitag, 3 janvier 2019). C'est peut-être la raison pour laquelle G. Dietrich insiste beaucoup sur la personnalité d'Anton Ackermann et sur le rôle qu'il a joué dans les premières années, en étant favorable à un socialisme démocratique sans dictature du prolétariat préalable. Ce passé d'historien de RDA est décisif pour comprendre cet ouvrage. G. Dietrich souhaite d'ailleurs écrire cette histoire de la politique culturelle en RDA en tant que « chroniqueur, historien et témoin en une seule personne» (p. XLI).

L'ouvrage de G. Dietrich est fondé sur l'idée que l'on n'a pas encore tout écrit sur la RDA, loin de là, contrairement à ce que l'on entend et lit parfois (on pense par exemple à l'historien Winkler). Il s'agit à bien des égards d'un ouvrage de défense qui veut réaffirmer que la RDA était une dictature mais pas seulement. L'auteur s'efforce de contrer la tendance à raconter la RDA en fonction de sa fin. Il s'agit de remettre en cause les conclusions hâtives sur le caractère inéluctable de sa fin, de "défataliser " la RDA, pourrait-on dire (même si lui-même n'utilise pas ce terme), en partant du principe que rien ne la prédestinait à finir par se fondre dans la RFA comme elle l'a fait, tout en montrant les fragilités du régime. Cela implique également, pour G. Dietrich, de privilégier une approche praxéologique et nuancée de l'histoire de la RDA. C'est ce qu'il résume par l'idée de «rendre la RDA plus ambivalente » («die DDR ambivalenzfähig zu machen ", p. XXVI).

Les césures choisies pour les trois tomes sont intéressantes car très inattendues: 1957/58 et 1976/77. G. Dietrich explique en introduction que ces césures sont culturelles et non pas politiques, mais on retrouve en fait des périodisations plutôt politiques (les différents plénums du comité central sont définis comme des souscésures, de même que les grands débats comme celui sur le formalisme en 1948). L'objectif de ne choisir que des césures culturelles et non pas politiques n'a donc pu être entièrement tenu. La césure de 1957/58 est liée à l'abandon d'une politique culturelle pour toute l'Allemagne, basée sur la notion de nation culturelle allemande, totalement récusée ensuite. Celle de 1976/77 n'est pas, dans l'esprit de G. Dietrich, liée tant à l'affaire Biermann et à ses conséquences, qu'à l'expansion de ce qui est considéré comme culture en RDA : le divertissement, la culture de consommation (Konsumkultur). On aurait pu attendre des césures plus évidentes, comme 1959 (Bitterfelder Konferenz) ou encore 1961, la construction du mur.

Il y a une volonté explicite de la part de G. Dietrich de transmettre des connaissances nouvelles sur la RDA que « les plus jeunes ne connaissent pas car ils n'apparaissent pas dans l'image actuelle de la RDA » (p. XLI). Cela lui a été reproché (lire par exemple IlkoSascha Kowalczuk, ). Ilko-Sascha Kowalczuk affirme qu'il n'y a pas « une image de la RDA », mais plusieurs : «Comme les cultures, l'image de la RDA n'existe qu'au pluriel. » Mais il faut pourtant reconnaître que l'approche de la RDA par les médias a souvent été très peu nuancée. L'histoire politique monolithique est longtemps restée l'option dominante de l'historiographie de RDA, notamment en RFA. Ce type d'approche est né de la convergence entre plusieurs facteurs : l'anticommunisme, la mise en avant de l'impératif pour les historiens d'œuvrer pour le travail sur l'histoire (Vergangenheitsbewältigung), l'ouverture rapide des archives avec les surprises que cela a provoqué, et aussi le fait que le débat parlementaire a parfois remplacé les experts. Tous ces éléments ont eu tendance à créer un consensus autour de la notion de totalitarisme, de sorte que les historiens voulant faire de la sociohistoire et étudier la 
société de RDA étaient soupçonnés de chercher à relativiser, voire nier, le caractère dictatorial du régime. Ceci n'est plus vrai aujourd'hui, mais les études sur ce que les jeunes savent de la RDA montrent bien que les clichés continuent à circuler et que G. Dietrich a raison de souligner la nécessité de corriger l'approche centrée uniquement sur l'appareil de répression.

Pour ce faire, il analyse pour chaque période trois aspects différents: la pratique quotidienne, la politique culturelle et les beaux-arts (Hochkultur). Il annonce en introduction qu'il va désolidariser ces trois aspects, et notamment déconnecter les pratiques culturelles de la politique culturelle, afin de distinguer la réalité vécue de la réalité idéelle, mais il n'échappe pas à la nécessité d'analyser à plusieurs reprises ces deux champs dans leurs interactions. On aurait par ailleurs souhaité qu'il synthétise davantage la politique culturelle de la RDA comme réconciliation de deux traditions allemandes (Kulturstaat et mouvement ouvrier), or il met toujours le Kulturstaat en avant. Le corollaire est que les aspects politiques et sociétaux sont sous-éclairés. Il y a par exemple très peu de choses sur le rôle du SED, des syndicats, des médias de RDA, des IM, de la censure et de « l'émigration intérieure ». La question du contrôle de l'art, de la dichotomie entre art politiquement souhaitable et art politiquement nuisible n'est pas analysée en profondeur. Cela nous oblige à réfléchir sur la possibilité de faire une histoire qui ne soit que culturelle et pas du tout politique. Ce sont, mutatis mutandis, et en exagérant un peu, les mêmes questions qui s'étaient également posées pour les shows télévisés sur la RDA qui avaient l'ambition de ne parler que du quotidien. G. Dietrich met l'accent sur les concepts importants de démocratisation, de culture de masse, de divertissement, de rééducation antifasciste, mais très peu sur l'idéologie. Il distingue de ce fait sept motifs :

1. Umerziehungsmotiv : la volonté de rééduquer par le moyen de l'art

2. Hochkultur : la culture classique réappropriée. Il y a des passages passionnants sur le romantisme, le rapport à Nietzsche, Luther et Müntzer, et à la Prusse.

3. Demokratisierungsmotiv : l'art comme outil de démocratisation, mais il ne mentionne pas les nouvelles discriminations.

4. Kampfmotiv : l'art est une arme, contre l'Ouest notamment.

5. Produktivitätsmotiv: G. Dietrich montre que le lien entre travail et culture et le rôle culturel des entreprises existaient bien avant Bitterfeld et sa formule célèbre « Prends la plume, camarade !».

6. Breitenkultur : La culture de et pour les masses.

7. Unterhaltungsmotiv: le divertissement, au début discrédité comme petit-bourgeois, puis accepté finalement à la fin des années 1970, et même dès le milieu des années 1960, où furent votées une réduction du temps de travail hebdomadaire et une augmentation du nombre de jours de vacances en RDA.

Malgré le caractère très volumineux de l'ouvrage, on peut regretter certaines lacunes. La culture au sein des Églises, comme le Thomanerchor de l'Église Saint Thomas de Leipzig par exemple, est à peine évoquée. Il passe très vite également sur les protestations contre la destruction de l'Église gothique Universitätskirche St. Pauli de Leipzig en 1968 (p. 1301). Il cite énormément, parfois sans commenter, des textes de conférences, de congrès, débats... et de ce fait parle moins des œuvres, ce qui est parfois frustrant. L'index des lieux et des personnes est très utile, mais en revanche, la 
bibliographie est étonnamment courte par rapport à l'ouvrage, il manque beaucoup de références pourtant citées en notes de bas de pages.

Il mentionne aussi certains artistes qui ont quitté la RDA, comme Rudolf Bahro, Wolf Biermann, Jürgen Fuchs, Sarah Kirsch et Gerhard Zwerenz, mais rapidement. Il semble ne pas considérer leurs œuvres comme faisant partie intégrante de la culture de RDA, ce qui fait écho à la polémique autour des auteurs de RDA exilés. Dans son autobiographie Der Widerspruch parue en 1974, Gerhard Zwerenz voulait explicitement faire partie de la littérature de RDA malgré son exil à l'Ouest et écrivait en substance : pourquoi la RDA serait-elle le seul pays au monde qui n'aurait pas de littérature étrangère, au sens d'une littérature d'auteurs habitant en dehors de ses frontières?

Par ailleurs, il y a très peu de réflexion méthodologique. Les références sur l'état de la recherche sont parfois incomplètes, et il cite des références d'historiens de RDA qui devraient être abordées avec une approche plus critique, même si évidemment il y avait des choses très importantes et intéressantes en RDA en matière d'écriture de l'histoire.

Enfin, l'ouvrage est presque exclusivement tourné vers l'intérieur, il y a très peu d'analyses sur la politique culturelle extérieure de la RDA. On peut regretter qu'il n'y ait pas de réflexion sur la spécificité de la culture de RDA, pas de comparaisons diachroniques avec l'Ouest, ni avec d'autres Républiques populaires. La RDA a tendance, de ce fait, à apparaître comme un objet qui existerait en soi et pour soi, coupé du monde, et notamment coupé de l'antagonisme pourtant structurant avec la RFA.

\section{INDEX}

Index chronologique : Époque contemporaine

Thèmes : Histoire de la culture, Histoire de l'art

\section{AUTEURS}

\section{ELISA GOUDIN}

Université Paris 3 - Sorbonne nouvelle 